\title{
A CASA DA SABEDORIA - UMA LEITURA DOS ESTATUTOS DA BIBLIOTECA PÚBLICA DE ÉVORA DE 1811
}

\author{
Francisco António Lourenço Vaz* \\ Departamento de História. Escola de Ciências Sociais da Universidade de Évora.
}

\begin{abstract}
Resumen: La Biblioteca Pública de Évora debe su fundación y sus valiosos fondos a la iniciativa de D. Manuel del Cenáculo. Los primeros años de la institución fueron marcados por la inestabilidad y la guerra, la biblioteca fue saqueada por el ejército francés en 1808 y una parte sustancial de su colección fue destruida. Con los Estatutos de 1811, el fundador dotaba la biblioteca de un financiamiento generoso y de personal que quería al servicio del público e de una colección de gran valor, no sólo libros, sino también obras de arte, antigüedades y productos naturales.

Con este trabajo se presenta un breve informe histórico de la biblioteca y analiza las ideas expuestas en su estatutos, comparándolos con la legislación y otros documentos nacionales e internacionales de cariz o bibliotecológico. También se evaluará el cumplimiento de un propósito establecido en el estatutos, convertir la biblioteca en una "Casa de la Sabiduría".
\end{abstract}

Palabras clave: biblioteca; casa de la sabiduría; bibliotecario; lectura pública; Évora.

Title: THE HOUSE OF WISDOM - A READING OF THE STATUTE OF THE PUBLIC LIBRARY OF ÉVORA IN 1811.

Abstract: Évora Public Library owes its foundation and its valuable collection to the initiative of D. Manuel do Cenáculo. The early years of the institution were marked by instability and war, the library was sacked by the French army in 1808 and a substantial part of his collection was destroyed. With the Statutes of 1811, the founder endowed the library of generous funding, a staff who wanted to serve the public and a collection of great value, not just books but also works of art, antiquities and natural products.

This paper presents a brief historical account of the library and discussed the ideas in their statutes, in comparison with the legislation and other national and international documents of librarianship. Also assess the fulfillment of a purpose set out in the Statutes, convert the library into a "house of wisdom".

Keywords: library; house of wisdom; librarian; public reading; Évora.

\section{INTRODUÇÃO}

A Biblioteca Pública de Évora foi fundada em 1805 por iniciativa de D. Frei Manuel do Cenáculo (1724-1814). Trata-se, portanto, de uma biblioteca bicentenária e de uma das mais importantes bibliotecas portuguesas, quer pelo seu passado quer pelo valor da sua

*fvaz@uevora.pt

Recibido: 05/06/2012; 2 $2^{\mathrm{a}}$ versión: 07/09/2012; aceptado: 10/09/2012.

LOURENÇO VAZ, F.A. A casa da sabedoria - uma leitura dos estatutos da Biblioteca Pública de Évora de 1811. Anales de Documentación, 2012, vol. 15, $\mathrm{n}^{\circ}$ 2. ISSN: 1697-7904. http://dx.doi.org/10.6018/ analesdoc.15.2.154091. 
coleção. Os primeiros anos da instituição ficaram marcados pela instabilidade e guerra, a biblioteca foi vandalizada pelo exército francês em 1808 e uma parte substancial da sua coleção foi destruída. Com a publicação dos Estatutos, em 1811, o Fundador concluía a sua obra, dotava a biblioteca de um orçamento generoso e de um quadro de pessoal, que queria ao serviço do público e digno duma "casa da sabedoria", onde reunira uma coleção de inegável valor, não apenas de livros, mas também de obras de arte, antiguidades e produtos naturais.

Os Estatutos abriram um novo ciclo, marcado pela esperança de transformar a biblioteca no local por excelência para todos os que pretendiam aventurar-se nos caminhos do conhecimento.

Com este trabalho comparamos os Estatutos com outras normas de cariz biblioteconómico, tendo em vista contribuir para a História das bibliotecas patrimoniais portuguesas, nomeadamente, no que se refere á importância das coleções, leitura pública e conservação de todo o seu espólio. Com a divulgação e debate sobre o passado recente da Biblioteca Pública de Évora, pretendemos, ainda, abrir hipóteses de intervenção no sentido de preservar e salvaguardar o património das instituições com responsabilidades bibliográficas e de o rentabilizar no contexto da sociedade de informação e da globalização em que vivemos.

\section{CONTEXTO HISTÓRICO E BIBLIOTECONÓMICO}

Em 1811 Portugal vivia no rescaldo das invasões francesas, o país ficara a ferro e fogo desde 1807, quando Junot entrou em Portugal. Nos anos que se seguiram, o território nacional passou a ser um dos palcos das guerras napoleónicas na Europa, a segurança das populações sempre ameaçada, o recrutamento militar de jovens e homens em idade de combater na ordem do dia. Para agravar ainda mais a situação, a família real transferira-se para o Brasil, e o país era dirigido por uma regência, que oscilava entre França e Inglaterra.

A cidade de Évora foi, à semelhança de muitas outras de Portugal, afetada pela invasão e ocupação estrangeira, logo durante a primeira invasão. De facto, em 1811 ainda estava bem viva a memória do saque de Évora, perpetrado pelo exército francês em 1808, durante os dias 29, 30 e 31 de Julho. Os textos que então se redigiram falam-nos das atrocidades, do vandalismo e destruição do património então praticado pelos soldados que eram comandados pelo general Loison, também conhecido como o maneta (Vaz, 2008, p. 13). Foram tempos difíceis, como são sempre os de ocupação e guerra, tempos a que não escapou a Biblioteca Pública, que tinha sido fundada por Frei Manuel do Cenáculo em 1805.

O próprio arcebispo sofreu na pele, primeiro porque o exército francês fez do paço episcopal a sede do comando e depois porque os revolucionários aproveitaram a conturbada situação política para se imporem à população. Gabriel Pereira descreveu com 
pormenor, recolhendo diversos documentos em especial os textos do secretário do arcebispo, os acontecimentos em que o prelado se viu envolvido, nos dias imediatamente posteriores. Eles permitem comprovar a «volta de Cenáculo»: a sua prisão, por ordem da Junta de Beja em 14 de Agosto de 1808, as manifestações de desrespeito para com o prelado, que contava então 84 anos e foi sujeito ao vandalismo das tropas dos revolucionários, que lhe roubaram o capote «esquadrinharam o escritório e obrigaram a «servir-se de uma janela para acudir as necessidades físicas» (Pereira, 1947, p. 8). Viviase o contexto revolucionário em que se extremavam e radicalizavam as posições. A Junta, a dar crédito no testemunho do Padre Gusmão, programava transferir a sede da Metrópole para Beja e investir como arcebispo o P. António Altar «um digno membro daquela infame Junta Jacobina». Conduzido para Beja, D. Manuel do Cenáculo foi passeado, como se de um troféu se tratasse, pelas ruas da cidade perante a chacota de uns e a tristeza de outros. Nesta cidade permaneceu preso no Convento de Santo António. Entre as iniciativas para o libertar sobressaíram os testemunhos, que os habitantes de Estremoz apresentaram ao secretário e que reconheciam que a cidade não fora saqueada pelos franceses porque o velho arcebispo os dissuadira desse empreendimento. Esses testemunhos foram enviados à Regência do Reino, que mandou ordem de libertar o arcebispo em 6 de Outubro de 1808. A libertação viria a efetivar-se no dia 16 desse mês, em que a escolta iniciou o regresso a Évora e, depois de pernoitar na Senhora de Aires, chegou à Sé de Évora às 11 horas do dia 17 de Outubro.

É impressionante como um ancião que passou por estes atropelos ainda encontre forças para concluir um dos seus projetos mais emblemáticos: a criação da Biblioteca Pública de Évora e a sua dotação financeira. Sem regulamento a obra não estaria completa, sem dotação financeira a obra não teria continuidade. Há na ação de D. Manuel do Cenáculo nesta matéria uma sequência lógica, que temos analisado em anteriores trabalhos, e que começou logo que tomou posse do cargo de arcebispo, em 1803, iniciando as obras para a biblioteca, a doação da sua coleção bibliográfica e museológica, prosseguindo depois com as iniciativas para alcançar a dotação financeira e finalmente o regulamento da casa, os Estatutos, que vemos como um autêntico testamento do fundador. No meio, os anos difíceis que vão de 1808 a 1811, três anos marcados pela violência e pela guerra, e que devem ter pesado mais do que a idade em Frei Manuel do Cenáculo, que tudo fizera para procurar fazer valer o diálogo e a paz.

A autoria dos estatutos pode não ser por inteiro de Frei Manuel do Cenáculo, o arcebispo contava 87 anos em 1811, e o seu diário nos últimos escritos mostram-nos uma mão debilitada, mas do que não temos dúvidas é que o prelado deu a sua aprovação a todo o conteúdo, provavelmente ditou-os ao seu bispo auxiliar, D. António José de Oliveira e, posteriormente, o escrivão passou-os para o livro de atas da Biblioteca.

A maior biblioteca do mundo da atualidade, a Biblioteca do Congresso dos Estados Unidos, teve a sua fundação, à semelhança da Biblioteca de Évora, no início do século XIX. A sua coleção inicial era muito incipiente, cerca de 740 volumes e 3 mapas. Passou igualmente por um momento de vandalismo, em 1814, quando os soldados britânicos 
incendiaram e pilharam a biblioteca. Em 1815 encontraria de novo a estabilidade necessária, nesse ano o Congresso ratificou a compra da livraria de Thomas Jefferson, de que resultou a incorporação de mais 6.487 livros, comprados pela quantia de 23.940 dólares. Nos seus primórdios a Biblioteca do Congresso contou igualmente com o impulso e as ideias de Thomas Jefferson, que lhe incutiu um cunho pragmático e nacionalista ${ }^{1}$, bem como assegurou o seu funcionamento e dotação financeira ${ }^{2}$. Portanto, é uma instituição contemporânea da Biblioteca de Évora, que passou também tempos conturbados e que por volta de 1815 não se podia comparar em termos bibliográficos com a riqueza e valor do espólio deixado por Cenáculo à biblioteca eborense.

Serve esta incursão e breve notícia histórica para demonstrar que o contexto de início do século XIX era pouco favorável ao desenvolvimento de projetos biblioteconómicos e, por outro lado, para nos mostrar dois modelos de desenvolvimento e ideia de biblioteca: a de Évora que se integra no contexto nacional e a do Congresso dos EUA que corresponde a uma nação jovem e como tal mais aberta a inovações. Voltaremos a esta questão mais à frente. Cumpre agora ler os Estatutos da Biblioteca Pública de Évora à luz do contexto nacional, ou seja, compará-los com outros regulamentos e normas legislativas que na época foram pensados para as instituições semelhantes.

Domingos Vandelli, professor italiano que veio para Portugal no tempo de D. José I, para lecionar no Colégio dos Nobres e depois passou para a Universidade de Coimbra, escreveu, a propósito de legislação agrária, que Portugal era a nação que tinha as mais sábias leis agrárias do mundo ${ }^{3}$, mas que em contrapartida em matéria de agricultura tinha um atraso considerável comparativamente às nações europeias. Esta mesma constatação podemos fazer relativamente a regulamentos, estatutos e outra legislação pensada para bom funcionamento das bibliotecas. Dois bons exemplos são Estatutos da Biblioteca Pública de Évora e o Alvará de 29 de Fevereiro de 1796 que criou Real Biblioteca Pública da Corte.

Consultámos muita da legislação relativa á criação e posterior implementação da Real Biblioteca Pública, depois Biblioteca Nacional de Lisboa, porque esta legislação era certamente do conhecimento de Frei Manuel do Cenáculo, quer porque o embrião da Real Biblioteca Pública começou na Real Mesa Censória e nos anos que Cenáculo a ela presidiu, e para a qual pensou um projeto de biblioteca a todos os títulos inovador; quer porque como Presidente da Mesa salvaguardou a transferência dos fundos das livrarias dos Jesuítas. Finalmente, porque Cenáculo contribuiu com avultado donativo para a Biblioteca Pública da Corte em 1797 e era amigo pessoal do bibliotecário, António Ribeiro dos Santos, com quem manteve correspondência (Vaz, 2009, p. 189-191). É assim de supor que ao pensar nos Estatutos para a Biblioteca Pública de Évora, o modelo ou inspiração que estava mais próximo era a legislação entretanto saída para criação e administração da Real Biblioteca Pública.

Muitas ideias são comuns aos Estatutos da Biblioteca de Évora e ao Alvará de 29 de Fevereiro de 1796 da Rainha D. Maria I: a vontade de assegurar uma dotação financeira, 
um quadro alargado e eficaz de pessoal, o reconhecimento da necessidade de uma permanente atualização bibliográfica, a ideia da biblioteca como local por excelência para aceder à sabedoria, ou a identificação da biblioteca como casa da sabedoria. Tomando como referência o percurso existencial e ideias de Frei Manuel do Cenáculo, esta comparação da biblioteca com a casa da sabedoria faz todo o sentido. A sabedoria é pensada como a virtude por excelência e um dos fundamentos para alcançar a docilidade dos costumes, ou a "felicidade e tranquilidade pública". No caso de Évora, esta invocação da sabedoria será mesmo materializada no edifício da biblioteca com a imagem de Nossa Senhora, colocada de forma significativa na sala de leitura e rodeada com o dístico: Sede Sapientia. Cenáculo deixou registo do ato no seu diário.

Fui assentar no seu lugar por cima da Porta da Livraria o Painel de Nossa Senhora cópia do original de Trevisani Mestre de Francisco Vieira português o antigo, a qual cópia é feita pela Princesa D. Maria Benedicta viúva do meu príncipe D. José. (Vaz, 2009, p. 604).

A Virgem aparece referida em alguns textos de D. Manuel do Cenáculo, em associação com a sabedoria e com o ensino, sendo o dia da Senhora das Candeias, celebrado a dois de Fevereiro, associada a festividades académicas, quer em Beja, quer depois em Évora quando implementou estudos no Colégio do Espírito Santo, a partir de 1804 (Vaz, 2007, p. 156).

A ideia de sabedoria em Frei Manuel do Cenáculo teve ainda outras fontes. O seu diário mostra-nos um assíduo leitor da Bíblia, que regista as suas leituras do Texto Sagrado com minúcia. Era certamente do seu conhecimento a descrição das qualidades excecionais que é feita no Livro da Sabedoria: «Brilhante é a sabedoria, e sua beleza é inalterável, os que a amam descobrem-na facilmente, e os que a buscam encontram-na. (...) Porque o seu princípio é um sinceríssimo desejo de instruir, e desejar instruir-se é já $a m a ́-l a \gg{ }^{4}$. Ou ainda, em outra passagem, o célebre discurso atribuído a Salomão, mas que os exegetas consideram não ser de Salomão, onde se exalta o valor da sabedoria quando comparada com as riquezas terrenas: «Não a comparei às pedras preciosas, porque todo o ouro ao lado dela é apenas um pouco de areia, e a prata comparada com ela, será considerada como lodo» 5 .

As ideias que os extratos bíblicos reforçam é a importância da vontade de instrução, como princípio básico de todo o saber e o valor incalculável do saber. Ou seja, quem trilha os caminhos da sabedoria aproxima-se de Deus e adquire uma riqueza incalculável. Há ainda uma máxima que podemos associar a este discurso, que fez escola durante o magistério baseado na escolástica e que pode ajudar a compreender o pensamento de Cenáculo, relativamente aos caminhos da sabedoria: " Scientia Donum Dei est, un vendi non potest”' (Burke, 2002, p. 1) ${ }^{6}$. Em nossa opinião, para Frei Manuel do Cenáculo a sabedoria fundamenta-se nos ensinamentos bíblicos, na "boa escolástica", está ao alcance de todos os que tem vontade de se instruir e, tal como a graça de Deus, é gratuita. Estes 
princípios traduzem-se em termos práticos na vocação pedagógica que pensa para a biblioteca, ao serviço da instrução e com acesso gratuito para todos.

Os Estatutos da Biblioteca de Évora e o Alvará de D. Maria I, comungam, também, da ideia, que foi herdada da Biblioteca de Alexandria, que se deve reunir na biblioteca não só os livros, mas também as antiguidades, moedas e mapas. A ideia que na época constituía o modelo, ou paradigma de biblioteca, é de facto a de uma biblioteca-museu, o que por um lado apresenta grandes vantagens, pois reunia-se num único espaço o essencial dos meios de informação disponíveis, desde os livros, manuscritos ou impressos, às obras de arte, peças arqueológicas, coleções de naturalia e monetário. Oferecia-se, deste modo, ao leitor várias possibilidades de aceder ao conhecimento. A verdade é que a biblioteca-museu apresentava, também, como os tempos vieram a comprovar, muitos inconvenientes, sobretudo no que diz respeito à conservação dos espécimes e, mais importante para a nossa análise, para assegurar um serviço público de leitura eficaz. É que além dos que demandavam a biblioteca para ler, vinham também os curiosos e os visitantes, que queriam apreciar a coleção museológica e que aproveitavam para ver também os livros. Se nos colocarmos na pele de um leitor que procurasse a sala de leitura da Biblioteca Pública de Évora, compreendemos melhor como era difícil em muitas circunstâncias ter condições para uma tranquila e confortável leitura.

A situação não era unicamente portuguesa, pois já bem entrado o século XIX, e numa das bibliotecas mais conceituadas da Europa, levantou-se uma querela entre um leitor e o bibliotecário. Referimo-nos ao conflito que opôs o escritor britânico Thomas Carlyle ao célebre bibliotecário da Biblioteca do Museu Britânico, António Pannizi, e que ocorreu precisamente pela falta de sossego e tranquilidade de leitura que o primeiro queria ver respeitado na sala de leitura da biblioteca (Popowich, 2007).

No caso da Biblioteca de Évora, os bibliotecários do século XIX, apontariam nos relatórios as dificuldades que resultavam desta dupla função da biblioteca. Filipe Simões seria o mais cáustico, mas a verdade é que mesmo após a fundação do museu, no início do século XX, a Biblioteca continuou a assegurar um serviço para visitantes. Finalmente, ambos os textos insistem no carácter público da biblioteca que será, de forma mais vincada nos Estatutos de Évora que precisarão melhor no artigo o horário de abertura ao público, enquanto o alvará da Rainha D. Maria I, de 29 de Fevereiro, remete essa decisão para o regimento que o bibliotecário fizer ${ }^{7}$.

Analisemos, agora, os Estatutos de 1811, para ver como foi pensada dotação orçamental, o quadro administrativo e o serviço de leitura pública. Pretendemos sobretudo responder a algumas questões: foi a dotação orçamental adequada? Correspondia o quadro de bibliotecários e restantes funcionários aos requisitos indispensáveis para assegurar a qualidade do serviço público? A atualização das coleções estava convenientemente salvaguardada? 


\section{OS ESTATUTOS DE 1811}

Os Estatutos da Biblioteca datam de 21 de Setembro de 1811 e com eles o fundador concluía a obra que desde que chegara a Évora em 1803 acalentava e tinha tido o primeiro grande momento com a conclusão das obras em 1805 e a colocação dos livros nas estantes da magnífica sala de leitura. As preocupações orçamentais com a Biblioteca, e a necessidade de dar ao público de "curiosos" o acesso à leitura dos livros e á observação das coleções, estão presentes desde muito cedo na ideia de Frei Manuel do Cenáculo (Vaz, 2006, p. 60).

Comecemos com as questões orçamentais. Os Estatutos vêm fixar a aplicação de 500.000 réis anuais, provenientes das rendas da Mitra e da Fábrica da Sé, para conservação e funcionamento da biblioteca. E desde já para sempre aplicamos para conservação, e adiantamento da mesma Biblioteca, e para ordenados de seus oficiais quinhentos mil réis; trezentos das rendas da Mitra, e duzentos da Fábrica cada um ano, as quais serão pagas em quartéis; para o que será lançada esta verba em folha fazendo-se os assentamentos nos Livros correspondentes ${ }^{8}$.

Há uma grande preocupação em definir os ordenados do quadro de funcionários e, nesta fase inicial, condiciona-se mesmo esse quadro à exigência de fazer o catálogo. Pelo que na prática se criam três lugares de bibliotecário, com o vice-prefeito a exercer as funções de bibliotecário, e a todos os três se recomenda com veemência a necessidade de fazer o catálogo 9 . De acordo com o determinado o pessoal afeto a Biblioteca e respetivos ordenados era o que consta do quadro seguinte. 


\begin{tabular}{|c|c|c|}
\hline Empregados & $\begin{array}{l}\text { Ordenado } \\
\text { Em réis }\end{array}$ & Funções estatutárias \\
\hline Prefeito & 100.000 & $\begin{array}{l}\text { «Presidirá sempre que a Biblioteca estiver aberta para o } \\
\text { serviço do público: ordenará quando deve ser feito para o } \\
\text { arranjo e boa ordem dela: dividirá quanto for necessário } \\
\text { para o governo económico, boa guarda, e limpeza dos } \\
\text { livros». }\end{array}$ \\
\hline Vice-prefeito & 100.000 & $\begin{array}{l}\text { «...deverá fazer as atas, e Memórias da Biblioteca, como } \\
\text { também toda a escrituração científica relativa à mesma, } \\
\text { tendo mais todo o ofício de Bibliotecário». }\end{array}$ \\
\hline $1^{\circ}$ Bibliotecário & 90.000 & $\begin{array}{l}\text { «Serão estes bibliotecários obrigados a estar na mesma } \\
\text { biblioteca sempre que ela estiver aberta para o serviço dos } \\
\text { concorrentes». }\end{array}$ \\
\hline $2^{\circ}$ Bibliotecário & 90.000 & $\begin{array}{l}\text { «Neste princípio de estabelecimento será a sua primeira } \\
\text { ocupação fazer o Catálogo da Livraria, e suas pertenças» }\end{array}$ \\
\hline Cartorário & 60.000 & $\begin{array}{l}\text { «Será obrigado a pôr em boa guarda todos os Títulos e } \\
\text { papéis pertencentes à Mitra por qualquer motivo; fazer } \\
\text { deles Catálogo e tê-los prontos nas ocasiões que forem } \\
\text { necessários». }\end{array}$ \\
\hline \multirow[t]{2}{*}{ Contínuo } & 60.000 & $\begin{array}{l}\text { «Será obrigado a abrir e fechar as portas da Biblioteca, } \\
\text { e ajudar os Bibliotecários em tudo quanto pelo Prefeito, e } \\
\text { eles for julgado necessário a seu arranjo» }\end{array}$ \\
\hline & 500.000 & \\
\hline
\end{tabular}

Tabela I. Funcionários da Biblioteca Pública de Évora. (Fonte: Estatutos Biblioteca Pública de Évora, 1811, in VAZ, 2009B, p. 77).

Como se vê todo o orçamento nesta fase inicial se esgotava no pagamento dos ordenados dos funcionários da biblioteca. Quando a catalogação estivesse concluída, ficaria vago um dos cargos de bibliotecário ${ }^{10}$, e embora a fatia mais importante do orçamento continuasse a ser aplicada no pagamento dos ordenados dos empregados, o que sobejava, ou seja, 100.000 réis, seria para despesas extraordinárias, pequenas obras, e para atualização bibliográfica. A mesma quantia, de 100.000 réis, seria inscrita por dotação orçamental do Estado no ano de 1863, para aquisição de obras modernas (Ribeiro, 1914, p. 163).

Faz sentido que comparemos esta dotação orçamental, o quadro de pessoal e respetivos vencimentos com o que foi previsto para a Real Biblioteca Pública mesmo tendo presente que se trata de estabelecimentos de dimensão diferente.

Um aspeto que é comum é o peso que no orçamento têm os recursos humanos. O decreto de 30-12-1801 dotava a Real Biblioteca Pública de uma consignação anual de 1.6000.000 réis para atualização das coleções. Se compararmos esta verba com os gastos com os ordenados dos funcionários, constatamos que só os 3 cargos superiores, $1^{\circ}$ Bibliotecário, $2^{\circ}$ Bibliotecário e Guarda-Mor, auferiam 1.400.000 réis anuais e, apesar de 
não termos conseguido apurar os gastos com o restante pessoal - mais 16 funcionários: 2 oficiais escriturários, 6 oficiais bibliográficos, 6 contínuos, 1 porteiro e 1 agente (Ribeiro, 1914, p. 163) - é de supor que o montante fosse muito mais avultado que o gasto com a atualização das coleções. Como vimos para a Biblioteca de Évora, os gastos com pessoal absorviam todo o orçamento.

A hipótese que gostaríamos de colocar é que as preocupações dominantes parecem centrar-se muito mais em assegurar os recursos para pagamento de pessoal, do que para conservação e atualização das coleções. Esta situação vê-se bem no conjunto de legislação que foi saindo relativamente à Biblioteca Nacional: notamos um predomínio de legislação, relativa às questões do quadro de pessoal ${ }^{11}$. Este predomínio pode ainda ser confrontado ou comparado com os ordenados de outras profissões ou grupos profissionais na primeira metade do século XIX. Os salários dos professores, do que hoje designamos ensino primário e secundário, foram determinados pela carta régia de 13 de Novembro de 1801 que estipulava que os professores de primeiras letras das vilas e lugares, que até então venciam o ordenado de 40.000 réis, vencessem dali em diante vinte mil réis mais; ficando a ser o seu ordenado anual de 60.000 réis; que os professores nas cabeças das comarcas vencessem 30.000 réis mais do que os outros, ficando o seu ordenado sendo de 90.000 réis e na cidade de Lisboa teriam o ordenado de 140.000 réis. Os professores das línguas latina e grega, de retórica e de filosofia racional e moral, tanto em Lisboa, como nas cabeças das comarcas, conservariam os mesmos ordenados que até então recebiam 100.000 réis na província e 240.000 em Lisboa (Vaz, 1993, p. 64) ${ }^{12}$.

Seria, ainda, interessante comparar os salários dos bibliotecários, com o das outras profissões. Percorrendo as páginas da Gazeta de Lisboa, sempre esclarecedoras em matéria de História Social, encontramos vários anúncios do seguinte teor: "Acha-se vago o Partido de Médico da Cidade de Miranda, cujo rendimento anual é de $120 \$ 000$ réis, e tem acesso ao de $180 \$ 000$ réis do Hospital da referida cidade: à Câmara da mesma pode dirigir-se quem a ele se quiser opor (Vaz, 1993, p. 65). Ou seja um médico na província auferia 300.000 réis de ordenado anual. Estes dados, permitem-nos constatar que os ordenados dos bibliotecários da Real Biblioteca Pública eram principescos, até porque quer António Ribeiro dos Santos, quer Agostinho de Macedo, tinham outros proventos. Do mesmo modo, os ordenados pensados para Évora, quer para os bibliotecários quer para os outros oficiais eram bastante apelativos; na prática o contínuo da Biblioteca ganhava tanto como um professor primário e os bibliotecários como um professor de Latim, para lá dos proventos inerentes a categoria de Bispo Coadjutor, ou Doutor da Terceira Ordem.

Neste domínio, portanto, o estatuto social dos bibliotecários no início de oitocentos era característico da elite do funcionalismo público ${ }^{13}$. Mas outro dado que convêm anotar é que a legislação não exige a estes profissionais a exclusividade e, pelo contrário, aceita a acumulação de funções. Em Lisboa, Agostinho de Macedo continua a exercer o cargo de professor régio de Filosofia e portanto a partir de 1801 passa a auferir a bonita soma de 600.000 réis de rendimento anual e no caso de Évora a situação persistirá com muitos dos bibliotecários, nomeados para dirigirem a biblioteca, a acumularem esta função com a de 
professores do liceu. Esta prática, que se iniciou com Cunha Rivara, continuou com os sucessores até meados do século $\mathrm{XX}^{14}$, em que muitos dos bibliotecários foram também professores de liceu. Não nos parece salutar este exercício simultâneo de funções. De facto, se considerarmos que ser bibliotecário é um cargo útil e de maior relevância para o progresso do país teremos de admitir que ele deve ser exercido de pleno direito e a tempo integral. A biblioteca devia exigir ao responsável máximo uma dedicação exclusiva e exigir que as autoridades políticas assumam a importância e relevância desses serviço com o salário e estatuto competente.

Nos Estatutos exige-se aos bibliotecários formação adequada para o exercício da função. Pode dizer-se mesmo que neste domínio o texto apresenta grande atualidade, dado que exige formação universitária: tal como se estipula no artigo $2^{\circ}$ : «Os Bibliotecários serão sempre pessoas de Literatura, devendo ter preferência os que forem graduados na Universidade, ou Mestres na sua Religião» ${ }^{15}$.

A atualização das coleções estava prevista e salvaguardada, ainda que com verbas muito diferentes. No caso da Biblioteca Nacional, a situação seria substancialmente melhorada com o Decreto de 12-9-1805, que determinou o depósito legal.

... que cada uma das leis, Alvarás, e de quaisquer outros papéis legais, conclusões, gazetas, correios e mais obras periódicas, e bem assim de todos e quaisquer folhetos, folhas volantes, avisos e anúncios; e geral e indistintamente de todos os impressos, de qualquer volume, e de qualquer matéria e natureza, e de qualquer corporação ou pessoa: se fizesse entregar de então em diante, um exemplar em papel na Biblioteca Pública de Lisboa pelos administradores ou diretores de todas as oficinas tipográficas destes reinos, públicas e particulares, ainda isentas e privilegiadas, de qualquer ordem e qualidade que fossem e em qualquer parte em que se achassem (Ribeiro, 1914, p. 130).

Esta foi, sem dúvida, uma medida de grande alcance futuro, mas as leis e provisões que se fizeram a este propósito, para o caso da Biblioteca Nacional, parecem demonstrar que foi uma medida de difícil implementação, e que muitos livreiros e editoras não estavam a cumprir estas exigências ${ }^{16}$.

Os Estatutos da Biblioteca Pública de Évora previam uma verba para a manutenção do edifício, gastos extraordinários e compra de livros, na prática 100.000 réis. Todo o resto dos quinhentos mil réis se conservará no cofre com a sua devida escrituração para servir as despesas extraordinárias de algum concerto do edifício, asseio dele, e dos Livros, compra de alguns, de papel, de penas, de tinta e de algumas coisas, que o tempo irá ensinando o serem necessários ${ }^{17}$.

Os Estatutos previam, ainda, a supervisão do trabalho dos bibliotecários e restantes funcionários, pelos responsáveis máximos da diocese, o arcebispo e o cabido, determinando que todos os anos, no dia da transfiguração de Jesus Cristo, celebrada a 6 de 
Agosto, esses dirigentes diocesanos visitassem a Biblioteca, para em "conferência" com os bibliotecários, averiguarem as faltas ou problemas de funcionamento e pensarem em estratégias de correção. Trata-se, portanto, de uma diretiva que comprova o que inicialmente dissemos: os Estatutos como autêntico testamento que o Fundador deu à instituição e no qual deixou exaradas as diretivas que garantiam o bom funcionamento e a continuidade da obra.

\section{CONSIDERAÇÕES FINAIS}

A Biblioteca do Congresso dos EUA começou, como referimos, com uma coleção incipiente, teve de comprar os livros do Presidente Jefferson, pagando caro por eles, foi atualizando as suas coleções e em duzentos anos transformou-se na maior biblioteca do mundo. Faz sentido que a consideremos o protótipo da casa da sabedoria. Pelo contrário, a Biblioteca de Évora, que contou com uma coleção atualizada e valiosíssima no seu início - os números apontam para cerca de 30.000 espécies, com obras raras, com numerosos incunábulos e mesmo uma Bíblia Moguntina, e uma coleção museológica impressionante - não foi capaz nestes 200 anos de salvaguardar todas as suas coleções, esteve até meados do século XX, dependente de benfeitores para atualização bibliográfica e, portanto, não a podemos ver como uma casa da sabedoria, mas antes como uma instituição que serviu os interesses conjunturais dos homens que por ela passaram.

Portugal é um país de excelentes regulamentos e estatutos, mas a prática institucional parece ser pouco eficiente. Porque é que tão bons regulamentos não se traduzem em instituições excelentes? Ou o que falhou, para que as nossas bibliotecas tenham ficado muito aquém de ser, ao longo destes 200 anos, os focos de instrução pensados pelos legisladores?

Gostaríamos de trazer a debate três hipóteses de resposta. A primeira foi apontada por Alexandre Herculano, como um mal crónico dos país no século XIX: o predomínio de um espírito literário sobre o sentido prático ou pragmático. Estas ideias do ilustre historiador foram apresentadas em 1840, durante o debate parlamentar sobre a criação da Escola Politécnica, contra a qual se afirmaram alguns deputados que pediam a restauração do Colégio dos Nobres (Vaz, 2002, p. 342). Muita retórica e pouca aplicação prática dos princípios. Por isso, os regulamentos, as leis e os estatutos, existem mas ignoram-se, são como "verbo de encher", e não há uma mentalidade de prestar contas. Este último facto vê-se por exemplo no caso da Biblioteca de Évora no tempo do consulado de Cunha Rivara. O Ministério do Reino exigia, desde 1840, relatórios anuais aos bibliotecários sobre o movimento de leitores e estado das coleções. Ora temos 5 relatórios para os 17 anos de exercício do cargo (Cerico, 2007, p. 103), o que é manifestamente insuficiente.

A segunda e especificamente com base na análise que fizemos da legislação oitocentista relativamente à Biblioteca Nacional, é o predomínio de uma mentalidade corporativa, que perpassa nas normas e regulamentos. As preocupações dominantes que aí divisamos referem-se a ordenados, lugares que vagam e que devem ser preenchidos e a 
grande fatia do orçamento vai para alimentar o quadro de pessoal. Não negamos que seja necessário um quadro efetivo de pessoal habilitado, mas as mordomias parecem-nos excessivas. Seria interessante neste domínio um estudo comparativos, com o que se passou com as bibliotecas nacionais europeias. Esta mentalidade corporativa tem ainda outra dimensão, e que leva os altos responsáveis das bibliotecas a verem a casa mais como propriedade sua do que dos leitores que a demandam. O caso de Évora demonstra bem essa mentalidade; durante o consulado de Cunha Rivara, era o bibliotecário que determinava quem podia ou não levar livros para casa (Cerico, 2007, p. 162).

A última hipótese prende-se com o que consideramos ser uma desvalorização do livro e da leitura que nos parece ser resultante dos seguintes parâmetros.

O primeiro é que os fundos iniciais das bibliotecas provêm de doações de benfeitores, ou de incorporações determinadas pelo Estado; caso de Évora, do Porto e também da Real Biblioteca Pública, que vê o seu fundo inicial vir diretamente das livrarias dos jesuítas. Parece-nos que esta situação incute na opinião pública a ideia traduzida no aforismo popular, "A cavalo dado não se olha o dente", ou seja, o que é dado não tem muito valor, não é fruto do nosso trabalho nem dos nossos impostos.

O segundo resulta de uma ideia de progresso característica de novos-ricos. É vulgar encontrar nos discursos dos bibliotecários, e até nas normas legislativas, a ideia de que o que é necessário e útil são os "livros modernos", que os livros de outras eras são ramos estéreis do conhecimento. Não negamos a necessidade de atualização bibliográfica, o que faltou foi manter um espírito de considerar os livros antigos como um valor, de riqueza e de conhecimento, se não de atualidade científica, pelo menos de grande valor documental e patrimonial.

O último assenta nos baixos níveis de leitura e de literacia da população portuguesa. Este é um facto que resulta de um dado estruturante do país durante o século XIX e que mergulha as suas raízes nas características sociais e politicas do Portugal moderno. De facto, apesar do discurso pedagógico apelar muito cedo à necessidade de uma instrução para todos ${ }^{18}$ e de o poder político liberal ter insistido na instrução popular, a verdade é que o país chegou a finais de oitocentos com o nível de alfabetização mais baixo da Europa (Carvalho, 1986, p. 614). Sem leitores pouco adianta ter a biblioteca de portas abertas, pouca utilidade têm os livros. Com efeito, o que os escassos dados estatísticos que nos chegaram demonstram são os baixos níveis de leitores nas nossas bibliotecas públicas.

Para que a biblioteca seja efetivamente uma "casa da sabedoria", tal como Frei Manuel do Cenáculo pretendia, é necessário que os profissionais sejam sábios e que os livros, independentemente de serem atuais ou de eras remotas, ou de serem de grandes ou de pequenos autores, ou mesmo de serem de luxo ou baratos, sejam sempre vistos como repositórios da sabedoria, estejam bem conservados como joias raras e sejam de fácil acesso para os leitores. 
Resta-nos esperar que o dinamismo que a biblioteca tem tido nos últimos anos contribua para repensar o valor dos seus fundos e das suas funções, de modo a cumprir os desígnios do seu fundador e dos seus primeiros estatutos.

\section{NOTAS}

1 «Jefferson believed that the power of the intellect could shape a free and democratic society. As a man who stated he could not live without books, he took a keen interest in the Library of Congress and its collection while he was president of the United States from 1801-1809». Jefferson Legacy. A brief History of the Library of Congress, disponível em: <http://www.loc.gov/loc/legacy/loc.html>. [Consulta: 10 de janeiro de 2012].

2 «On January 26, 1802, Pres. Thomas Jefferson approved the first law defining the role and functions of the new institution. This measure created the post of Librarian of Congress and gave Congress, through a Joint Committee on the Library, the authority to establish the Library's budget and its rules and regulations». Idem, ibidem.

3 «Nação alguma nos seus Códigos, ou nos seus Arquivos, tem tantas sábias Leis Agrárias, providencias e representações dos Povos para florescer a Agricultura, que este Reino» Domingos Vandelli, 1777-1794, cit. VAZ, Francisco, Instrução e Economia. As Ideias Económicas no Discurso da Ilustração Portuguesa, Lisboa: Colibri, 2002, p. 441.

${ }^{4}$ Bíblia, Livro da Sabedoria' 6, 11-12 e17.

${ }^{5}$ Bíblia, Livro da Sabedoria. 6, 7-9.

6 «O conhecimento é um dom de Deus e portanto não se pode vender».

7 No entanto quer na utilização contínua do epíteto "pública" associado à Biblioteca, quer pelas palavras reforçase o carácter público da instituição: «E quero que o uso especial, e próprio desta Biblioteca seja o de ser perpetuamente destinada ao bem das Letras, e beneficio contínuo dos Meus Vassalos». SILVA, António Delgado da, Coleccção da Legislação Portuguesa-Legislação de 1791-1801, Lisboa, Typografia Maigrense, 1828, p. 796.

${ }^{8}$ Estatutos da Biblioteca Pública de Évora, transcritos por: VAZ, Francisco, D. Manuel do Cenáculo: Instruções Pastorais, Projectos de Bibliotecas e Diário, Porto: Porto Editora, 2009, p. 74.

9 «Neste princípio de estabelecimento será a sua primeira ocupação fazer o Catálogo da Livraria, e suas pertenças; o qual será feito com a perfeição que é de esperar dos hábeis sujeitos que empregamos, conferindo-se tudo com o Perfeito». Estatutos da Biblioteca Pública de Évora, in VAZ, Francisco, D. Manuel do Cenáculo: Instruções Pastorais, Projectos de Bibliotecas e Diário, Porto: Porto Editora, 2009, p. 77.

10 «E por isso ordenamos que o primeiro que vagar, depois de feito o Catálogo, não seja mais provido o seu lugar, e do ordenado que vagar, se acrescentarão mais dez mil réis ao de cada um dos outros que restam, recaindo o mais para acrescentar a porção que fica para o fundo da Casa. Terá de ordenado cada um dos Bibliotecários oitenta mil réis, por ora, devendo ter noventa depois da primeira vagatura». Estatutos da Biblioteca Pública de Évora, Idem, Ibidem.

${ }^{11}$ O decreto de 4-3-1796 nomeou bibliotecário maior o Dr. António Ribeiro dos Santos. O decreto de 5-3-1796 nomeou segundo bibliotecário Agostinho José da Costa Macedo, professor de Filosofia em Lisboa. A ordem de 8-6-1796 aplica em benefício da biblioteca as multas aos empregados da mesma. O aviso de 29-1-1801 determinou que as mesadas dos oficiais da biblioteca fossem pagas na Tesouraria Geral dos Ordenados. Com o decreto de 12-3-1821 as Cortes determinaram que os oficiais bibliógrafos, ajudante do guarda-mor, contínuos e porteiro vencessem de ordenado mais metade do salário que até aí ganhavam (em virtude de se ter alargado para seis horas e em todos os dias o horário de leitura, quando anteriormente abria de forma alternada: segundas, quartas, quintas e sábado de manhã das 9 ás 13 e nas terças, sextas de tarde das 15 ás 17). A portaria de 18-3-1823 extinguiu os cargos de guarda-mor e ajudante de guarda-mor, reduziu o número de contínuo a 4 . O aviso de 18-51825 restabeleceu os 2 lugares de contínuos que tinham sido extintos em 1823. O decreto de 8-4-1834 nomeou bibliotecário-mor Vasco Pinto de Sousa Balsemão. A portaria de 11-6-1834 determinou que se pagasse por inteiro o quartel aos empregados demitidos; o decreto de 19-7-1834 reorganizou o quadro de pessoal: 1 bibliotecário-mor, 3 conservadores, 6 oficiais (ajudantes dos conservadores), 2 contínuos (ajudantes dos oficiais), 2 contínuos, 6 oficiais supranumerários. A portaria de 5-5-1835 indicou as habilitações para provimento dos lugares vagos na biblioteca. O decreto de 29-9-1836 extinguiu 2 lugares de conservadores e mais 2 de oficiais 
ajudantes. O decreto de 7-12-1836 aprovou o regulamento da biblioteca, proposto pelo bibliotecário-mor, com as competências dos oficiais e empregados da casa. A carta de lei de 13-8-1853 autorizou a biblioteca a gastar até 345.000 réis, além da verba já prevista no orçamento, com o pagamento de " trabalho braçal", por parte de empregados fora do quadro. A carta de lei de 14-8-1860 elevou o ordenado anual do porteiro da biblioteca para 240.000 réis. A carta de lei de 11-7-1863 reorganizou o quadro de pessoal da biblioteca: um total de 22 funcionários (não contando com empregados temporários e regente da cadeira de numismática); o total dos gastos era de 9.004.400 réis. Foi depois consignada a verba aplicada à atualização bibliográfica, que continuava a mesma de 1.600.000 réis, agora para compra de obras fora do reino. Cf. RIBEIRO, José Silvestre, Apontamentos históricos sobre bibliotecas portuguesas organizado e antiloquiado por Álvaro Neves, Lisboa: Academia Real das Sciências, 1914, p. 157.

12 Para os vencimentos de professores, antes de 1801, veja-se: ADÃO, Áurea, Estado Absoluto e Ensino das Primeiras Letras. As escolas Régias (1772-1794), Lisboa: Fundação Calouste Gulbenkian, 1997, p. $286-292$.

${ }^{13}$ A constituição de 1822 determinava que para se ser eleitor devia ter-se de rendimento anual 100.000 réis, e para se puder ser eleito deputado o rendimento era de 200.000 réis. Ora como se constata os bibliotecários da Biblioteca Nacional reuniam as condições para ser deputados só com os seus vencimentos e em Évora podiam ser eleitores.

14 Assim, logo a seguir a Rivara foram nomeados os seguintes professores do liceu: João Rafael de Lemos (1855), Augusto Filipe Simões (1863), José Maria Queiroz Velosa (1898), António Joaquim Lopes Silva (1902), Alberto Jordão Marques da Costa (1915). Veja-se: ESPANCA, Túlio, "Subsídios para a História da Biblioteca Pública de Évora”, Revista a Cidade de Évora, 63-64 (1981-1982), p. 203-204.

${ }^{15}$ Estatutos da Biblioteca Pública de Évora, cit. Vaz, 2009B, p. 76.

${ }^{16}$ Cf. lei de 20 de Setembro de 1822, estipulando a multa de um pagamento de valor correspondente a 20 exemplares da obra em falta (Ribeiro, 1914, p. 134). O alvará de 30-12-1824, que corroborou as determinações anteriores e a multa de 20 exemplares. O alvará de 28 de Maio de 1834 acrescentou a obrigação do depósito legal para as estampas e os mapas litografados (idem, p. 138). Em 1859 o bibliotecário-mor publicou aviso sobre a obrigação de fazer cumprir o depósito legal. RIBEIRO, José Silvestre, Apontamentos históricos sobre bibliotecas portuguesas organizado e antiloquiado por Álvaro Neves, Lisboa: Academia Real das Sciências, 1914, p. 149.

17 VAZ, Francisco, coord, D. Manuel do Cenáculo: Instruções Pastorais, Projectos de Bibliotecas e Diário, Porto: Porto Editora, 2009, p. 78.

18 VERNEY, Luís António, Verdadeiro Metodo de Estudar, Valensa: Na Oficina de Antonio Balle, 1746, t. 2, p. 50 .

\section{BIBLIOGRAFIA}

ADÃO, A. Estado Absoluto e Ensino das Primeiras Letras. As escolas Régias (17721794), Lisboa: Fundação Calouste Gulbenkian, 1997, p. 286-292.

Bíblia Sagrada, Lisboa: Difusora Bíblica, 1998.

BURKE, P. A Social History of Knowledge. From Gutenberg to Diderot. Cambridge: Polity Press, 2002.

CARVALHO, R. de. História do Ensino em Portugal. Lisboa, F. Gulbenkian, 1986.

CENÁCUlO, M. do. Cuidados Literários. Lisboa: Officina de Simão Thadeo Ferreira, 1791.

CERICO, P.C. da S. Cunha Rivara, um Bibliotecário Romântico, Dissertação de Mestrado em Arquivos Bibliotecas e Ciências da Informação apresentada à Universidade de Évora, Évora, 2007.

ESPANCA, T. Subsídios para a História da Biblioteca Pública de Évora. Revista a Cidade de Évora, 1981-1982, n ${ }^{\circ} 63-64$, p. 193-267. 
Gazeta de Lisboa, Lisboa, Officina de António Rodrigues Galhardo, 1805 (30-4).

Jefferson Legacy. A brief History of the Library of Congress. [En línea]. Disponível em: <http://www.loc.gov/loc/legacy/loc.html>. [Consulta: 10 de janeiro de 2012].

NORONHA, J.F. de C.B. Relatório Acerca da Biblioteca Nacional e mais Estabelecimentos Annexos. No $1^{\circ}$ de Janeiro de 1844. Lisboa : Typographia Lusitana, 1844.

POPOWICH, A.S. Carlyle, Panizzi, and the Public Library Ideal. Library Student Journal, February, 2007. Disponível em: <http://www.librarystudentjournal.org/index.php/ lsj/article/view/41/50>. [Consulta: 7 de julho de 2011].

PEREIRA, G. Estudos Eborenses. História e Arqueologia. Évora: Edições Nazareth, 1947.

RIBEIRO, J.S. Apontamentos históricos sobre bibliotecas portuguesas organizado e antiloquiado por Álvaro Neves. Lisboa: Academia Real das Sciências, 1914.

SILVA, A.D. da. Colecção da Legislação Portuguesa- Legislação de 1791-1801. Lisboa: Typografia Maigrense, 1828.

VAZ, F. Instrução e Economia. As Ideias Económicas no discurso da Ilustração Portuguesa. Lisboa: Colibri, 2002.

VAZ, F. e CALIXTO, J.A. (coord.), D. Frei Manuel do Cenáculo Construtor de Bibliotecas, Vale de Cambra: Caleidoscópio, 2006.

VAZ, F. «D. Frei Manuel do Cenáculo e o ensino no Colégio do Espírito Santo», REVUÉ. Revista da Universidade de Évora. 2009, no 10-11, p. 146-159.

VAZ, F. As Ideias Pedagógicas em Portugal nos Fins do século XVIII - Bento José de Sousa Farinha, Dissertação de Mestrado apresentada à Faculdade de Ciências Sociais e Humanas da Universidade Nova, Lisboa, 1993.

VAZ, F. O Saque de Évora pelos Franceses em 1808. Textos Históricos. Vale de Cambra: Caleidoscópio, 2008.

VAZ, F. (coord.). Os Livros e as Bibliotecas no Espólio de D. Frei Manuel Do Cenáculo. Lisboa: Biblioteca Nacional de Portugal, 2009.

VAZ, F. (coord.) D. Manuel do Cenáculo: Instruções Pastorais, Projectos de Bibliotecas e Diário. Porto: Porto Editora, 2009B.

VERNEY, L.A. Verdadeiro Metodo de Estudar. Valensa: Na Oficina de Antonio Balle, 1746 (2 tomos). Disponivel em: <http://purl.pt/118/2/sc-50680-v/sc-50680v_item2/index.html>. [Consulta: 23 de abril de 2012]. 